\title{
Distinguish between two Species of streptococcus by sk gene
}

\author{
Rawaa Kh. Mohammed ${ }^{1}$, Harith K. Buinya ${ }^{2}$ \\ ${ }^{1}$ M.Sc. Student, ${ }^{2}$ Assist. Prof., Department of Biology/College of Education for Pure Sciences/ \\ University of Anbar/Anbar-IRAQ
}

\begin{abstract}
This study aims at the possibility of using the $s k$ gene encoding the Streptokinase protein to differentiate between the different species belonging to the genus Streptococcus which can produce this protein., 12 bacterial isolates belonging to the genus Streptococcus were obtained, and by using thecaseinolytic assay test, all the studied isolates gave a positive result with different clear zone diameters around the wells. DNA was then extracted from the isolated bacteria and used as a template for the amplification of the $s k$ gene using specific primers for the gene. The $1300 \mathrm{bp}$ was amplified as PCR product comparing them with the DNA ladder. The target gene was obtained from of $S$. pyogenes and $S$. dysgalactiae subsp. equisimilis. . The result was confirmed by identifying the gene sequences and comparing it with the database in NCBI, which showed a similarity of more than $98 \%$ and the percentage of similarity between the genes of the different species was more than 99\%. The $s k$ gene for both species were digested with BtgZI and MboII restriction enzymes. The results of the agarose gel electrophoresis showed that the gene belonging to the $S$. pyogenes possesses restriction sites for BtgZI restriction enzymes that differ in location from that of the $S$. dysgalactiae subsp. equisimilis. Where the bundles appeared in different locations, which means that the location and number of restriction sites differ between the two types, and this feature can be used to differentiate between them.
\end{abstract}

Keywords: Sk gene, Streptokinase, Streptococcus.

\section{Introduction}

In view of the many changes occurring in the patterns of life, whether social or economic in general, in the world, an increase in the rates of many coronary heart diseases, caused by blood clotting in the arteries of the heart, which sometimes leads to death, has been observed. It leads to the stopping of blood circulation, in the physiological state, fibrin and platelets are used for clotting to prevent blood loss during injuries in a process called blood clotting $] 1[$. Because of the high economic cost of tissue plasminogen activators, it was necessary to using the low expensive and more available, and since there are some bacterial species also have the ability to produce proteins play role as a plasminogen activators like Streptokinase and Staphylokinase $]^{2}$. The pathogenic bacteria differ in seriousness Infecting humans and animals according to the virulence factors they produce, so work has been made to convert the most dangerous virulence factors to humans and animals into effective compounds that can be used in the treatment of many diseases through the use of genetic engineering techniques $^{[3]}$. An important virulence factor in causing hemolysis, which is secreted by some bacterial species, is the streptokinase protein (SK) produced by some types of hemolytic streptococci of the genus Streptococcus, as it has been used as a treatment in dissolving blood clots as in cases of myocardial infarction since 1959 and in the treatment of Peripheral arterialocclusive since 1974 and is now widely used in many countries of the world ${ }^{44}$.

The streptokinase protein encodes for the sk gene, which has a size of $1.3 \mathrm{k} \mathrm{bp}{ }^{35}$. it was first isolated in 1933 from a Streptococcus broth culture and named Streptococcal fibrinolysin ${ }^{6[}$. The term Streptokinase was used for the first time in 1945, and the amino acid sequence was fully determined by Jackson and Tang ]7[ . It is an extracellular protein secreted by hemolytic streptococcus bacteria (GAS), (GCS) and (GGS). It is a single-chain protein consisting of 414 amino acids with a molecular mass of $47 \mathrm{kDa}$ that has the ability to bind to plasminogen and form a streptokinase plasminogen complex. This complex turns plasminogen into active plasmin that breaks down fibrin, which is the main protein for blood clots ${ }^{8[}$.SK is not in itself a plasminogen activator, but rather binds to free-circulating 
plasminogen or with plasmin to form a complex that can convert another plasminogen into a plasmin ${ }^{[9]}$.

The aim of the study was to differentiate the different types of Streptococcus bacteria using the $s k$ gene.

\section{Materials and Method}

Samples Collection: Bacterial isolates were collected from the laboratories of Al-Amiriya General Hospital (Al-Anbar) and the educational laboratories in the City of Medicine (Baghdad), from various pathological conditions (Table 1). The isolated diagnosis by Biochemical test ${ }^{[10,11]}$ and confirmed with the Vitek-2 Compact.

\section{Table (1) Types and numbers of bacteria isolated and belonging to the genus Streptococcus.}

\begin{tabular}{|c|l|c|}
\hline $\begin{array}{c}\text { No. of } \\
\text { isolates }\end{array}$ & Isolates & \\
\hline 1 & Streptococcus pneumoniae & 1 \\
\hline 2 & Streptococcus agalactiae & 2 \\
\hline 5 & Streptococcus mutans & 3 \\
\hline 1 & Streptococcus suis & 4 \\
\hline 2 & Streptococcus pyogenes & 5 \\
\hline 1 & S.dysgalactiaesubsp. equisimilis. & 6 \\
\hline
\end{tabular}

The ability of bacteria to produce Streptokinase: To find out the ability of bacteria to produce streptokinase, a caseinolytic assay test was used. Broth culture of 18 hr. isolates was prepared. $1 \mathrm{~mL}$ of bacterial culture was taken from each culture and placed in a $1.5 \mathrm{ml}$ Eppendorf tube. The cells were sonicated with an ultrasound machine and a portion of the shattered culture was used in caseinolytic assay. Mix $36 \mathrm{ml}$ of buffer solution (mMTris- HCL/150 mMNaCl) with $400 \mathrm{mg}$ of agarose and after dissolving by heat add $2 \mathrm{ml}$ of skim milk with $1 \mathrm{ml}$ of blood plasma. It was mixed well and was poured into a petri dish. Well of $5 \mathrm{~mm}$ was made in the plate and 50 microliters were loaded from each sonicated culture in the well and incubated for 18 hours at $37^{\circ} \mathrm{C}$. the clear zone around the wells was measured ${ }^{[12]}$.

Chromosomal DNA extraction: DNA was extracted from various types of Streptococcus bacteria by (Genomic DNA extraction kit) from Geneaid Company. Process was done according to the instructions of the provider. Electrophoresis was carried out using a $1 \%$ agarose gel, where the samples were carried over with a voltage difference of 100 millivolts for an hour, and the DNA was investigated by exposing it to a UVtransilluminator with a wavelength of 256 nanometers.

Gene amplification and Purification: The sk gene was amplification by Polymerase Chain Reaction (PCR) using DNAisolated from bacterial isolates using specific primers for $s k$ gene (Forward:GGGA TTCCATATGATTGCTGGACCTGAG). (Reverse: CCGGAATTCTTATTTGTCTTTAGG) ${ }^{[13]}$.

The PCR device was programmed according to the steps taken by Bustin, 2004, after which an electrophoresis was performed using agarose gel at a concentration of $1.2 \%$ to read the products of the PCR reaction. Then, Purification was done using Gel/PCR DNA Fragments Extraction Kit .To purify the polymerase chain reaction products of the $s k$ gene, the purification process was done according to the instructions of the provider.

Gene Sequencing: The PCR product were sequenced in Macrogen company(South Korea) using a Genetic Analyzer to obtain the gene sequences. The data were analyzed by Mega 7 software and compared with Ref. sequences which published inNCBI.

Restriction Enzyme: The restriction enzymes (BtgZI and MboII) were procured from NEBI (USA) and used according to the instructions of the supplying company.

\section{Results and Discussion:}

Caseinolytic assay test: Table (2) and Figure (1) show the results of the caseinolytic assay for Streptokinase activity after $18 \mathrm{~h}$ incubation at $37^{\circ} \mathrm{C}$.

Table (2) Dimensions of dissolution in caseinolytic assay test for isolated bacteria

\begin{tabular}{|c|l|c|}
\hline & Isolate & Diameter of zone \\
\hline 1 & Streptococcus pneumoniae & $6 \mathrm{~mm}$ \\
\hline 2 & Streptococcus agalactiae & $10 \mathrm{~mm}$ \\
\hline 2 & Streptococcus agalactiae & $12 \mathrm{~mm}$ \\
\hline 4 & Streptococcus mutans & $11 \mathrm{~mm}$ \\
\hline 5 & Streptococcus mutans & $14 \mathrm{~mm}$ \\
\hline 6 & Streptococcus mutans & $15 \mathrm{~mm}$ \\
\hline 7 & Streptococcus mutans & $9 \mathrm{~mm}$ \\
\hline 8 & Streptococcus mutans & $12 \mathrm{~mm}$ \\
\hline 9 & Streptococcus suis & $15 \mathrm{~mm}$ \\
\hline 10 & Streptococcus pyogenes & $5 \mathrm{~mm}$ \\
\hline 11 & Streptococcus pyogenes & $6 \mathrm{~mm}$ \\
\hline 12 & S.dysgalactiae subsp.equisimilis & $9 \mathrm{~mm}$ \\
\hline
\end{tabular}



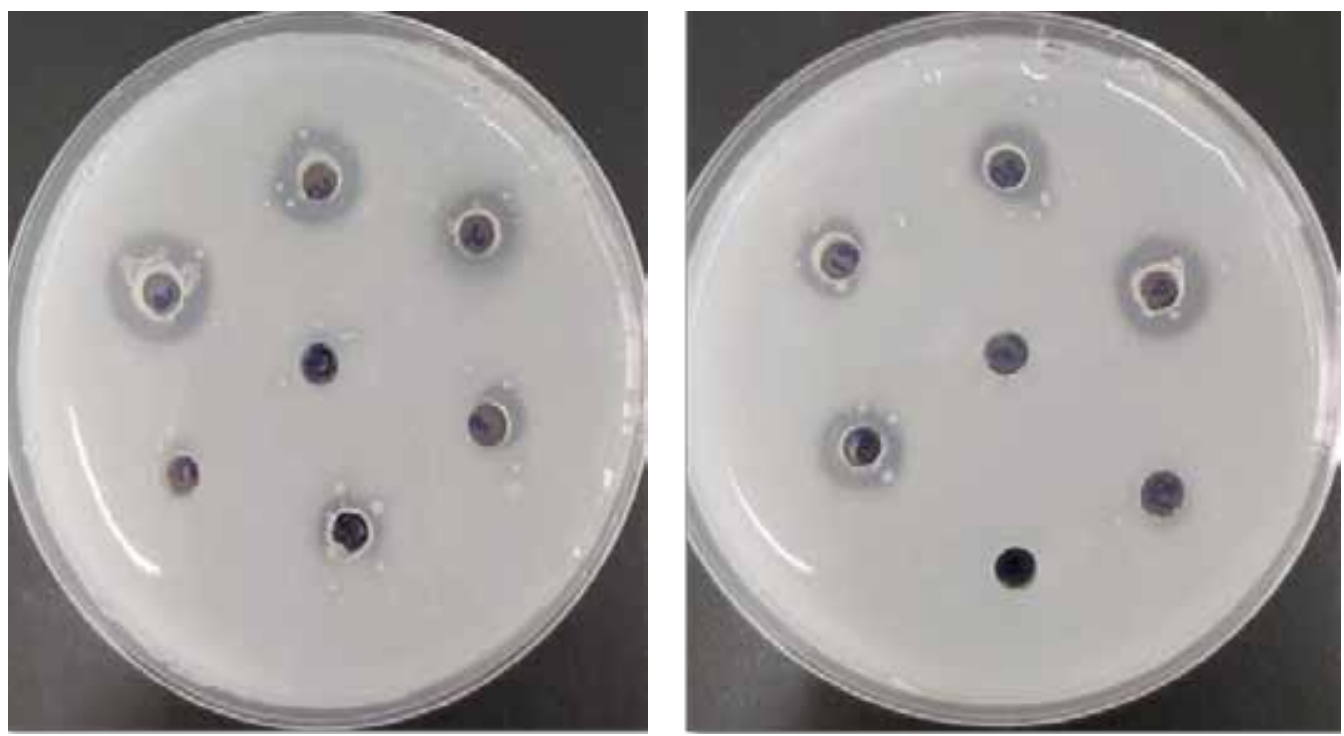

Figure (1): The result of caseinolytic assay and transparent area formation around the wells.

Chromosomal DNA extraction: The agarose gel electrophoresis at a concentration of (1\%) showed the emergence of a single bund representing the chromosomal
DNA of the different species of the Streptococcus genus, which was detected using ultraviolet radiation and an ethidium bromide stain (Figure 2).

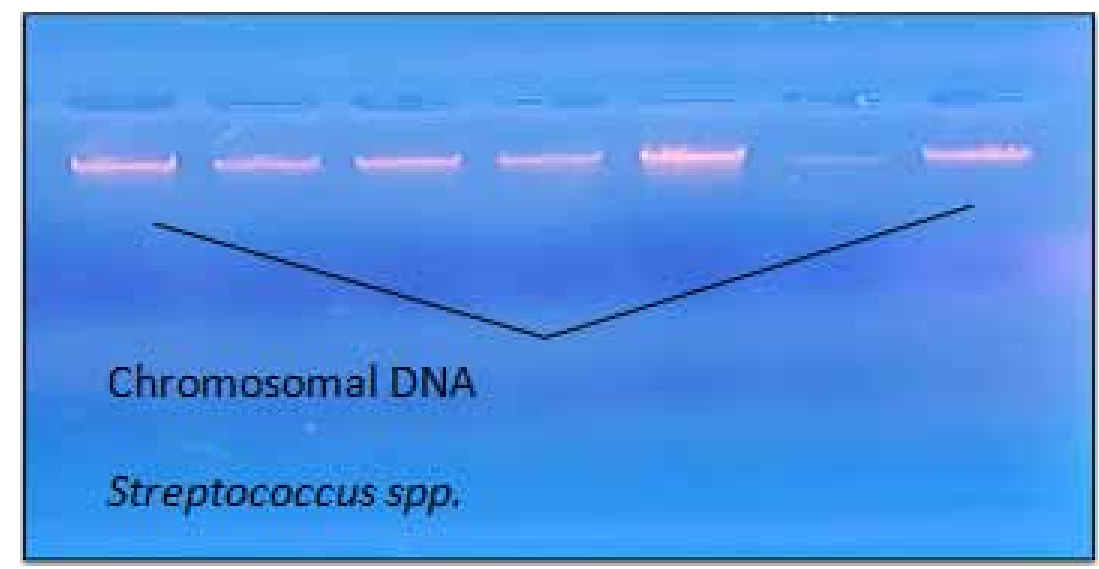

Figure (2): Agarose Gel Electrophoresis (1\%, $100 \mathrm{~V} / \mathrm{cm} / 60 \mathrm{~min}$.) for Chromosomal DNA extracted from different species of Streptococcus bacteria.

Gene amplification and purification: The results showed that the targetgene was obtained from three isolates: Streptococcus pyogenes, Streptococcus pyogenes and S.dysgalactiae subsp.equisimilis. As for the other isolates, the reaction was carried out more than once, but the target fragment of the gene was not obtained even though the isolates gave a positive result in the caseinolytic assay test. The reason for not obtaining the $s k$ gene from the rest of the bacterial isolates may be attributed to the fact that the isolates may not possess the gene because they are not affiliated with the bloodanalyzing bacterial strains of the Lancefield groups A, C, G.

Since the isolates in which the gene was isolated belong to the aforementioned bacterial strains and are of type A, C, and G, then this study is identical to previous studies, as all of them confirmed that all hemolysis bacterial strains belonging to the mentioned types contain the gene encoding to produce Streptokinase ${ }^{[15],[16],[17]}$. 
Then, the process of purification of the polymerase chain reaction products of the $s k$ gene was carried out using a Gel/PCR DNA Fragments Extraction Kit and electrophoresis on a $1.2 \%$ agarose gel for one hour and detected under ultraviolet irradiation and the ethidium bromide, the following result showed in figure (3) .

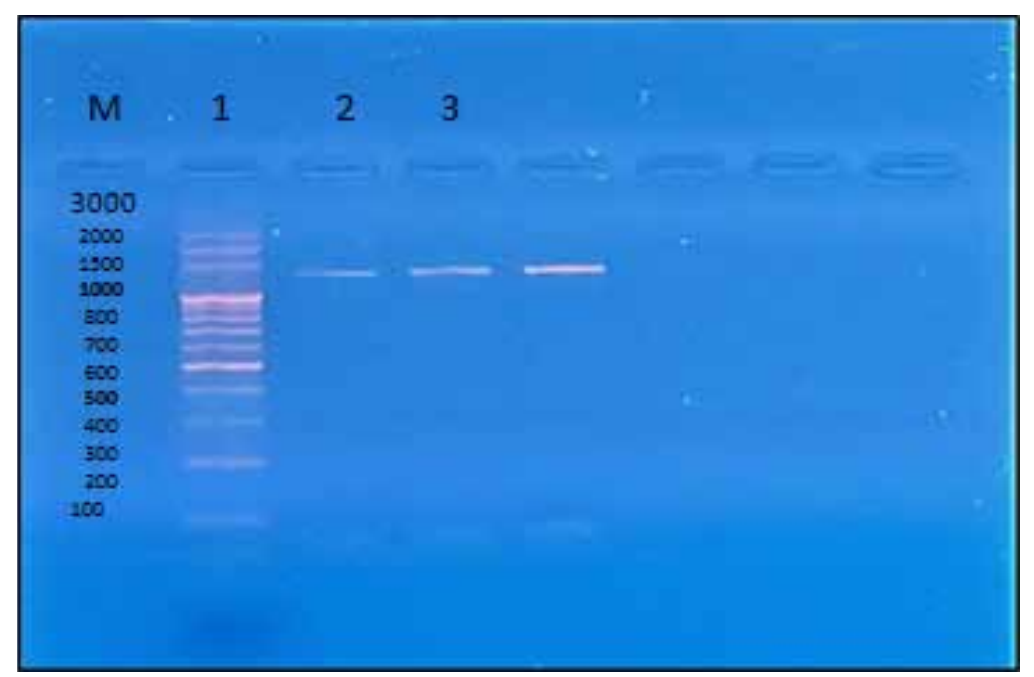

Figure (3): Gel Electrophoresis $(1.2 \%, 100 \mathrm{v} / \mathrm{cm} / 60 \mathrm{~min})$ for PCR products for the Streptokinase encoded sk gene after gene purification using a Gel extraction kit. M: 100 bp DNA marker 1 : S. pyogenes $2: S$. pyogenes 3 : S. dysgalactiae subsp. equisimilis

sk gene sequences: The PCR products were sent to Macrogen in South Korea, to determine the nitrogen base sequences of the DNA fragment of 1300 bp by the Sanger and Coulson method, or called the chain termination method. The results obtained from the company were then matched with the database at the National Center for Biotechnology Information (NCBI). The similarity between $s k$ gene and their counterparts in NCBI were more than $98 \%$ for both species.

A comparison was also performed between the skgene sequences of $S$. pyogenes and $S$. dysgalactiae subsp. equisimilis using the Mega 7 program, and the result was almost $99 \%$.

Restriction Enzyme: The result of electrophoresis of the $s k$ gene of $S$. pyogenes and $S$. dysgalactiae subsp. equisimilis . After treatment with the Restriction enzyme BtgZI, there was a difference in the position of the bundles on the agarose at a concentration of $1.5 \%$. This gives an indication that the location of the BtgZI Restriction enzyme sensitive sequence in the gene belonging to the $S$. pyogenes is in a different location on the gene map than the location of the sensitive sequence for the same enzyme for the gene belonging to $S$. dysgalactiae subsp. equisimilis. The size of the DNA fragment removed from the gene in the $S$. dysgalactiaesubsp. equisimilis was larger than the size of the fragment of DNA that was removed from the gene of S. pyogenes after being treated with the restriction enzyme Figure (4) .

When the sk gene was treated with the MboII restriction enzyme for both types, there was no apparent difference in the size of the gene after treatment, and this may be due to the fact that the electrophoresis on the agarose gel does not give clear separation of the bundles of DNA segments with a difference of less than $50 \mathrm{bp}^{[18]}$. Therefore, the use of vertical electrophoresis with SDS gel is better to separate DNA fragments whose size difference is less than 50 base pairs.

By reviewing the studies on the $s k$ gene, we did not find any study indicating the possibility of differentiating the different types of the Streptococcus by treating the sk gene with restriction enzymes despite the presence of susceptible sites for many restriction enzymes in the gene sequences recorded in NCBI. Through our current study, it became possible to distinguish between the different species belonging to the genus Streptococcus through the $s k$ gene after treatment with restriction enzymes. 


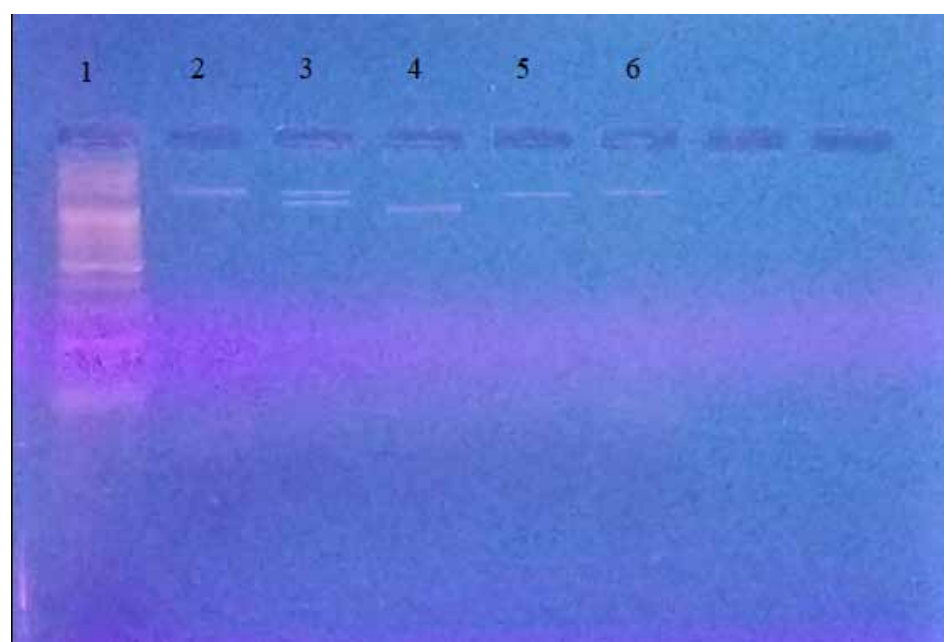

Figure (4) Agarose Gel Electrophoresis (1.5\%, $100 \mathrm{v} / \mathrm{cm}, 60 \mathrm{~min}$.) forsk gene restricted byBtgZI and MobII Restriction Enzymes at a concentration.

1-100 bp DNA Ladder 2- The $s k$ gene is not treated with restriction enzymes 3-skgene for $S$. pyogenes treated with BtgZI4- skgene for S. dysgalactiae subsp. equisimilis with BtgZI5- skgene for S. pyogenes with MboII6- skgene for S. dysgalactiae subsp. equisimilis with MboII.

\section{Conclusions}

The results of the detection of the $s k$ gene in betahemolytic bacterial isolates belonging to types $\mathrm{A}, \mathrm{C}$, and $\mathrm{G}$ are consistent with the results that all hemolysis bacterial strains of the aforementioned species contain the gene encoding the production of Streptokinase. Also, all of the studied Streptococcus isolates gave a positive result of the caseinolytic assay test, and this may give an indication of the presence of proteins having similar activity to that of Streptokinase. It was also found that the sequences of the $s k$ gene were identical to what was published in the NCBI database at a rate of more than $98 \%$, and at the same time, the sequences of the same gene belonging to two different species had a difference of less than $0.5 \%$. The $s k$ gene contains sensitive sites for many restriction enzymes, through which it was possible to distinguish between the different strains of the Streptococcus genus through the $s k$ gene after treatment with the $B \operatorname{tg} Z I$ restriction enzyme.

Ethical Clearance: The Research Ethical Committee at scientific research by ethical approval of both environmental and health and higher education and scientific research ministries in Iraq

Conflict of Interest: The authors declare that they have no conflict of interest.

Funding: Self-funding

\section{Reference}

1. Bhardwaj S, Angayarkanni J. Streptokinase production from Streptococcus dysgalactiae subsp. equisimilis SK-6 in the presence of surfactants, growth factors and trace elements. 3 Biotech. 2015 Apr 1;5(2):187-93..

2. Roohvand Farzin. Streptokinase for Treatment of Thrombotic Disorders: The end or the end of the beginning. Iranian Biomedical Journal, 2018, 22(3), 140 .

3. Keramati Malihe, Aslani Mohammad Mehdi, Roohvand Farzin. In silico design and in vitro validation of a novel PCR-RFLP assay for determination of phylogenetic clusters of streptokinase gene alleles in streptococci groups. Microbial Pathogenesis, 2020, 139: 103862.

4. Baruah Dev B. et al. Plasminogen activators: a comparison. Vascular pharmacology, 2006, 44.1: $1-9$.

5. Malke Horst, Ferretti Joseph J. Streptokinase: cloning, expression, and excretion by Escherichia coli. Proceedings of the National Academy of Sciences, 1984, 81.11: 3557-3561.

6. Tillett William S and Garner RL. The fibrinolytic activity of hemolytic streptococci. The Journal of Experimental Medicine, 1933, 58.4: 485-502. 
7. Jackson Kenneth W, Tang Jordan. Complete amino acid sequence of streptokinase and its homology with serine proteases. Biochemistry, 1982, 21.26: 6620-6625.

8. Wang Zihui, Yu Xinge, LI Yang V. Zinc chelation promotes streptokinase-induced thrombolysis in vitro. International Journal of Physiology, Pathophysiology and Pharmacology, 2017, 9.5: 137.

9. Abed Hayder H, Alwasiti Estabraq Ar, Tawfeeq Amir T. Streptokinase Loading Fabrication Magnetic Nanoparticle Supported With Tannic Acid As A Modified Thrombolytic Agent. Annals of Tropical Medicine and Health, 2019, 22: 34-47.

10. Benson HJ. Antimicrobial sensitivity testing: the Kirby-Bauer method. Microbiological Applications. Laboratory Manual in General Microbiology, 7th ed. McGraw-Hill, Boston, Massachusetts, 1998, 139-141.

11. McFadden JF. Biochemical Tests for Identification of Medical Bacteria, Williams and Wilkins. Philadelphia, PA, 2000, 113.

12. Remmert LeMar F, COHEN Philip P. Partial purification and properties of a proteolytic enzyme of human serum. Journal of Biological Chemistry, 1949, 181.1: 431-448.

13. Buniya Harith K, Murugan Vadivel, Thangadurai
Chinnathambi. Cloning and expression of hybrid streptokinase towards clot-specific activity. Journal of Microbiological Method, 2014, 98: 84-88.

14. Bustin, S A. (Ed.). AZ of quantitative PCR. La Jolla, CA: International University Line, 2004, 439-492.

15. Kazemi Faegheh et al. Computational simulations assessment of mutations impact on streptokinase (SK) from group $G$ streptococci with enhanced activity-insights into the functional roles of structural dynamics flexibility of SK and stabilization of SK- $\mu$ plasmin catalytic complex. Journal of Biomolecular Structure and Dynamics, 2019, 37.8: 1944-1955.

16. Turner Claire E, Bubba Laura, Efstratiou, Androulla. Pathogenicity Factors in Group C and G Streptococci. Gram-Positive Pathogens, 2019, 264274.

17. Keramati Malihe, ASLANI Mohammad Mehdi, Roohvand Farzin. In silico design and in vitro validation of a novel PCR-RFLP assay for determination of phylogenetic clusters of streptokinase gene alleles in streptococci groups. Microbial Pathogenesis, 2020, 139: 103862.

18. Green Michael R, Sambrook Joseph. Analysis of DNA by agarose gel electrophoresis. Cold Spring Harbor Protocols, 2019, 2019.1: pdb. top100388. 